\title{
Organ procurement in Israel: Lessons for South Africa
}

\author{
M Slabbert, ${ }^{1}$ BA (Hons) HED, B Proc, LLB, LLD; B Venter, ${ }^{2}$ LLB, LLM \\ 'Department of Jurisprudence, University of South Africa, Pretoria, South Africa \\ ${ }^{2}$ Faculty of Law, Midrand Graduate Institute, Midrand, South Africa
}

Corresponding author: B Venter (bonniev@mgi.ac.za)

\begin{abstract}
Modern medicine makes it possible to transplant not only kidneys but any solid organs from one human body to another. Although it is the ideal to harvest organs from a brain-dead person, a kidney or a part of the liver or lung can be transplanted from a living donor to a patient. The majority of countries where organ transplants are performed have a dire need for transplantable organs as the current systems of organ procurement are not obtaining a sufficient amount of transplantable organs. Today's cruel reality is that many patients are dying while waiting for a transplant. Few nations are able to meet the organ demand through their domestic transplant systems and there is a constant debate about ethical ways of procuring organs for transplantation purposes. This article will scrutinise the Israeli system of organ procurement and it will be compared with the current system of organ donation in South Africa (SA) in order to indicate whether SA could possibly, or should, follow the example of Israel to improve its acute donor organ shortage.
\end{abstract}

S Afr J BL 2015;8(2):44-47. DOI:10.7196/SAJBL.444

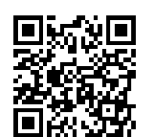

Since the first kidney transplant a new chance of life has been created for many dialysis patients. Modern medicine makes it possible to transplant not only kidneys but any solid organs from one human body to another. Although it is the ideal to harvest organs from a brain-dead person, a kidney or a part of the liver or lung can be transplanted from a living donor to a patient. The majority of countries, where organ transplants are performed, have a dire need for transplantable organs as the current systems of organ procurement are not obtaining a sufficient number of transplantable organs. Today's cruel reality is that many patients are dying while waiting for a transplant - this is an unfair and sad reality of life. ${ }^{[1]}$ Few nations are able to meet the organ demand through their domestic transplant systems and there is a constant debate about ethical ways of procuring organs for transplantation purposes. All organ donations are mainly altruistic, meaning there are no financial incentives for people who are willing to have their organs or the organs of their deceased family member used for transplants. Unfortunately the altruistic supply of organs has been less than adequate and the gap between supply and demand has worsened over time. ${ }^{[2]}$

Globally countries either follow an 'opting-in' or an 'opting-out' organ procurement system. ${ }^{[3]}$ 'Opting-in' is an altruistic form of organ donation where the organ donor either donates an organ as a living person after giving informed consent, or as a deceased person, having given consent to a donation pre-mortem. ${ }^{[4]}$ 'Opting-out' is a system where every citizen of a specific country is automatically an organ donor unless the individual registers his or her objection to being an organ donor. ${ }^{[4]}$ Opting-out mainly concerns deceased donors. If a donor in an opting-out system wants to donate a kidney as a living person, informed consent is still necessary. ${ }^{[5]}$

Direct payment for an organ donation is illegal in nearly all countries. It is also condemned by the World Health Organization ${ }^{[6]}$ and the Declaration of Istanbul[ ${ }^{[7]}$ although both allow the reimbursement of costs in relation to the donation. ${ }^{[8]}$ It should be noted that the
Declaration does not provide explicit support for donor incentives. The fundamental idea of the Declaration, signed by 78 countries around the world (including South Africa (SA)) is striving to achieve self-sufficiency in organ donation by providing a sufficient number of organs for residents in need, from within the country, while blocking transplant tourism by banning its reimbursement. Singapore ${ }^{[0]}$ has recently begun to compensate living donors according to their Human Organ Transplant Act, but it has not yet succeeded in eliminating the kidney shortage. This Act determines, in section 14(3), that the organ donor may be reimbursed for costs incurred by the donation. It is not a direct payment to the organ receiver and an ethics committee determines the total amount that the receiver should pay to the organ donor. Iran focuses on living donors and they pay the donors, in contravention with the rest of the world, but their donor waiting list is longer than the list of people waiting for a transplantable organ. ${ }^{[10]}$ Iran also has laws in place that protect the basic rights of the paid donors. ${ }^{[1]}$ Israel has also decided to address the organ shortage in their country as their rate of deceased organ donations is one of the lowest when compared to other developed countries. ${ }^{[12]}$ Only $16 \%$ of adult Israelis signed donor cards and $45 \%$ of families consented to deceased donation, yielding a very low rate of 6 - 9 per million population (the current population is around 8 million), compared to $35 \%, 25 \%$ and $17 \%$ in Spain, France and the UK respectively. ${ }^{[12]}$ Their new Organ Transplant Act has enabled them to develop a unique system without paying the donor directly, although they allow some form of financial compensation for living donors. ${ }^{[13]}$ This article will scrutinise the Israeli system of organ procurement and it will be compared with the current system of organ donation in South Africa (SA) in order to indicate whether SA could possibly (or should) follow the example of Israel.

\section{Israel's Organ Transplant Act 2008}

In order to address the shortage of transplantable organs in Israel, a committee, including transplant physicians, coordinators, lawyers, 
philosophers, ethicists and representatives of the main religions was established. Their recommendations resulted in new transplant legislation for Israel. ${ }^{[14]}$

In January 2010 the new law governing organ donation and allocation, the Organ Transplant Act 2008, came into effect. ${ }^{13}$ The aim of the Act is mainly to increase the number of organ donations by introducing a priority system. The Act itself does not enshrine the details of the system, as this should be done at policy level. According to the Israeli system a person (or people on a waiting list) can gain priority points by:

- signing a donor card pre-mortem

- making a non-directed/non-specified organ donation during their lifetime

- way of a first-degree relative signing a donor card or consenting to procurement of organs after death. ${ }^{[14]}$

The priority system means that you will be treated with priority should you need an organ for transplantation purposes. In other words it gives you preferential status and an increased chance of receiving a donor organ should you be in need of an organ transplant. The system functions on the premise that justice demands that those who are willing to receive an organ should also be willing to donate one. ${ }^{[13,15]}$

The priority received by way of one of the above three ways is subdivided into maximum priority, regular priority and second priority. Maximum priority is granted to a candidate if he or she has given consent for an organ donation from a deceased first-degree relative or the candidate has donated a kidney, a liver lobe, or a lung lobe as a living donor to a non-specified recipient. Regular priority is granted to candidates who hold a donor card, in other words those who have consented to donate their organs after their death. Second priority is granted to candidates with a first-degree relative who hold a donor card, even if they do not hold a donor card themselves. ${ }^{[13,16]}$

The Act also allows for a form of compensation for living donors. Compensation to living donors covers 40 days of lost wages and up to 30000 shekels for proven medical expenses, up to 5 years. These include transportation costs, supplementary and private medical insurance, disability insurance, life insurance, five psychological treatment sessions and a week-long convalescence vacation. ${ }^{[17]}$

Israel is also the first country in the world to reward deceased organ donors. For deceased donors the National Organ Transplantation Centre bears the burial costs. The law also authorises the Health Ministry to offer a reward to a person for agreeing to donate the deceased person's organs. ${ }^{[12]}$ Satel ${ }^{[18]}$ gives an example of how deceased donors' families are rewarded. A family of a man that was declared brain dead received an amount of 10000 Israeli shekels in recognition of the wife's decision to allow his liver, kidneys and lungs to be taken for transplantation. The money comes from the company's charitable contributions and it may be used in any way the family see fit to memorialise the deceased. The director of the company, who gave the money to the wife, said when he handed the money over: 'in this country we always talk about military heroism ... [T] his is clearly a case of civilian heroism. [His organs] saved four lives ... [the] family should be blessed! ${ }^{[18]}$ Even though the Israeli system seems to be a solution to organ procurement the process raises some concerns.

\section{Concerns about the new Act}

The Act treats a living donor the same as someone who has given consent that organs from a first-degree deceased relative may be used for transplantation. This creates the perception that the moral good of living donations are aligned with permission to use a deceased person's organs. The system also does not allocate points to living donors who have directed their donation to a loved one, for example a mother to a child. ${ }^{[13,19]}$ The sacrifice a living donor makes cannot be compared with just giving consent for a donation to take place from a deceased body of a first-degree relative, as it cannot be equated with the risk of a living donation.

'Directed living donors assume risk during their lifetime to aid another human being. In doing so, they shorten the waiting list by one: they help not only their recipient but everyone else waiting for an organ ... the Israeli system treats previous living donors inequitably. ${ }^{[14]}$

It therefore seems very unfair not to give priority points for directed living donations and to equalise a living undirected donation with permission to use organs of a deceased first-degree relative. ${ }^{[14]}$ One's chances of obtaining priority points also depend on how many firstdegree relatives a person has which automatically disadvantages those with fewer siblings, something which is beyond a person's control. ${ }^{[14]}$ According to Quigley et al. ${ }^{[14]}$ this aspect of the allocation system involves an element of unfairness as the more siblings one has, the greater the likelihood of giving consent to a donation. Also those with fewer potential living donors will have to wait for an organ from a deceased donor, but within the new system of priority points they are less likely to gain enough points based on the actions of their relatives.

It is globally accepted that transplantable organs should be allocated to those with the greatest medical need. The priority point system moves away from this principle as it restricts access to a transplantable organ to those individuals who participate in the point system above those with a medical need. ${ }^{[13]}$ This means that an adult who signs up to be an organ donor prior to the time when he or she needs an organ will be given priority over another adult in need of the same organ who had not previously signed up to be a donor. Principles of equity and justice are therefore compromised by taking non-medical factors into account in determining which patients should receive an organ off the transplant waiting list. ${ }^{[13]}$

The incentive of priority points, based on having a donor card or a first-degree relative having a donor card, is not offered for the actual organs but for the promise that they will be available for transplantation after death. People could therefore just join the donor register to get priority points while they at the same time inform their relatives that they do not wish to donate organs after death. ${ }^{[14]}$ This is an important point of criticism as the Israelis follow an opting-in system in which the consent of first-degree relatives is obtained when a person dies, even if the person who has passed away had a signed donor card him- or herself. ${ }^{[14]}$ Because Israel is the first country to implement priority points, no evidence exists whether the above will happen; ${ }_{i}^{[14]}$ only time will tell. Yet, the other side of this argument could be that relatives can consent after the person's death to a donation even though they knew the deceased did not want to donate. Their decision could be influenced by getting extra priority points for themselves; it therefore gives them an incentive to donate a loved one's organs. This raises questions regarding the primacy of individual autonomy. ${ }^{[14]}$

\section{Positive aspects about the new Israeli law}

Since the introduction of the Act, Israel has witnessed a record number of people signing donor cards and there has been a 
significant increase in the actual number of transplants. The system reflects a communitarian model where everyone stands to benefit from cooperation, whereas the purely opting-in system without any rewards is very much founded on personal autonomy. The system can also be seen as 'reciprocal altruism' and 'a signal of solidarity by sharing organs as public good rather than as an exercise of a quasi-property right! ${ }^{\prime[13]}$ From a utilitarian perspective it seems a win-win situation and the system does away completely with 'free riders'.[13]

In the past Israeli insurance companies and sick funds have reimbursed transplant operations performed anywhere in the world, regardless of where the donors were from or the legality of the operations. ${ }^{[20]}$ The new law bans such reimbursement for organ transplantations, where the procurement of the organs were against the local laws or where organs have been involved in organ trafficking. [17] The Act precisely defines the circumstances of organ trade and trafficking and declares it a criminal offence punishable by 3 years' imprisonment, together with a large fine. ${ }^{[17]}$ Israeli patients travelling to venues like China for deceased heart or liver transplants have stopped completely since the inception of the new law. ${ }^{[17]}$

It is illegal to broker a transaction between potential living donors and recipients. ${ }^{[17]}$ To avoid the Israeli system being labelled a commodification of the human body, Israeli authorities label the financial reward to living donors as compensation for the donor's pain and suffering as opposed to payment for an organ. ${ }^{[17]}$ Israel has also chosen specifically not to follow the Iranian model of paid organ donation. ${ }^{[2]}$

The implementation of the new Israeli law was accompanied by extensive media campaigns. The general public was educated about the importance of organ donations. The public was also informed about approaches within Jewish tradition that allow organ donations and even see it as a religious imperative to save lives. ${ }^{[21]}$ Despite the arguments for and against the new Israeli system the biggest achievement is that fewer people are dying waiting for a transplantable organ. SA needs more donors and despite campaigns in the media, the waiting list increases every year, especially the need for kidneys, which could be resolved by using more living donors. The problem seems to be altruism as few people would give up a kidney purely to help another person. Maybe incentives might be the solution.

\section{Lessons for SA}

In SA, approximately 10000 people, young and old, of all ethnicities die of kidney disease or kidney failure every year. ${ }^{[2]}$ Others are luckier and can be treated by means of renal dialysis or a kidney transplant. A kidney transplant may sound like a straightforward solution but unfortunately kidneys for transplantation are a very scarce resource. Waiting times for a new kidney vary but can currently be estimated at anything between 6 to 12 years. ${ }^{[23]}$ In 2014, 213 kidney transplants were performed ${ }^{[24]}$ but only 93 kidneys were from a living donor - a living donor includes a related and non-related donor. This is an alarming statistic if one keeps in mind that SA has a population of nearly 54 million people.

The requirements for lawful kidney transplantations are to the utmost extent regulated by legislation such as the Constitution of the Republic of South Africa, 1996 and the National Health Act of 2003 (hereafter referred to as the Act) as well as the regulations in terms thereof. Section 60 of the Act imposes a strict limitation on the buying and selling of organs, which underlines the fact that all donations should be regarded as a 'gift of life'. According to Section 60(4)(a) of the Act:'It is an offence for a person who has donated tissue, a gamete, blood or a blood product to receive any form of financial or other reward for such donation, except for the reimbursement of reasonable costs incurred by him or her to provide such donation' Yet, section 60(4)(a) of the Act stipulates that a donor may receive a reimbursement of reasonable costs incurred to provide a donation. Unfortunately neither the Act, nor the regulations determine who will be liable for these costs or what exactly 'reasonable costs' entail. In this regard SA has a similar clause to Singapore's Human Organ Transplant Act but the Singapore Act follows specific guidelines of what the reimbursement entails, for example: travelling costs, medical expenses and time lost at work. Because of this lack of clarity in the National Health Act, guidance could be sought in the Constitution, specifically section 39(1) which states when interpreting the Bill of Rights, international law must be considered and foreign law may be considered. In other words SA could consider how other countries have interpreted the payment of 'reasonable costs' in connection with an organ transplant.

Within one year after the implementation of the new legislation in Israel there was a significant increase in the number of organ donors, from 7.8 to 11.4 donors per million population, in parallel to a significant increase in the number of new registered donors that rose by 71229 donors. ${ }^{[17]}$ Transplant tourism has also sharply decreased from 155 kidney transplantations being performed abroad to a mere 35 in one year. These statistics clearly illustrate that SA can improve its acute organ shortage by taking a leaf from Israel's book regarding their new organ procurement system. The priority point system, as discussed above, with its concerns and positive aspects cannot be applied as it is currently in SA as it does not have a national database of either organ donors or people in need of organs. Organ transplants are also not a priority for the Department of Health. The allocation of points will therefore be a major obstacle, in other words the Israeli system although it has positive aspects is not the ideal solution for SA but what SA can learn from them is that government intervention in changing their legislation made a huge difference to the patients waiting for an organ in Israel.

There are a number of points that SA can assimilate from the Israeli approach. First, it should be noted that SA's organ transplantation legislation forms a minute part (15 of 94 sections) of the National Health Act, one Act that provides a framework for the entire health system in SA. Israel, and the majority of countries excelling in the field of organ donation, follow a different approach and their organ transplantations are governed by an entirely separate act. ${ }^{[25]}$ Second, the Israeli Organ Transplant Act makes provision for the establishment of a database at the Transplant Centre that shall contain the details of both people waiting for an organ as well as the particulars of people who indicated their willingness be an organ donor. SA does not have a national waiting list nor does it have any form of consolidated database - every transplant hospital has its own separate database of recipients waiting for a lifesaving organ. Thirdly, the Israeli Transplant Act makes provision for the reimbursement of a living and deceased donor. According to section 22 of the Act a uniform sum of money will be paid to all living organ donors as compensation for the monetary loss reasonably attributable to the procedures associated with organ removal. The Act also further stipulates, in section 30, that the burial costs as well as the transportation of the deceased organ donor's body 
will be paid for. This is not done in SA and might not be an option as there are too many other aspects needed in place before payment can even be considered. Lastly, the Israeli Act makes provision for the motivation and recognition of organ donors. According to the Act the donor shall be awarded a certificate of recognition and shall receive other benefits such as being exempted from entrance charges to national parks. ${ }^{[26]}$ The Israelis will also receive priority under the priority point system discussed earlier. SA legislation does not provide for the motivation or recognition of organ donors which is evident when looking at long-standing substandard organ donation statistics.

It can clearly be deducted from the discussion above that Israel realised that a dire need for transplantable organs exists, and took a decision to address the problem and seek a solution for their acute organ shortage. There may be flaws and criticism against Israel's preferred system but one thing that cannot be argued is that there has been a significant improvement in their organ transplantation numbers. It can currently be argued that SA's transplant legislation and regulations are not aimed at finding a suitable solution for the overwhelming need for transplantable organs. Organ transplants are not regarded as a priority in the SA health system, even though $20 \%$ of the population suffers from major health problems that can lead to kidney failure. ${ }^{[27]}$ It will be reprehensible if the shortfall of legislative development, as discussed above, is the only reason why South Africans waiting for a transplantable organ are left hopeless.

\section{Conclusion}

The challenge of every organ procurement system is to design a policy that will increase the supply of transplantable organs without creating social segregation, discrimination or coerced retrieval. ${ }^{[13]}$ The Israeli system, if successfully implemented, would represent a landmark change in organ donation and allocation and set an example from which we could learn. ${ }^{[13]}$ In 2011 Israel saw an unprecedented increase in consent for donations and a record number of 70000 people signed a donor card. Transplants have increased by $68 \% .{ }^{[14]}$

Any improvement is worthwhile, as an economist at George Mason University said: '... too much attention [is] placed on eliminating the shortage and that if you haven't eliminated the shortage you haven't solved the problem. [Yet], every attempted solution doesn't have to solve the problem 100 per cent'. $\left.{ }^{\prime} \cdot 28\right]$

\section{References}

1. Cantarovich F. Reducing the organ shortage by education and fostering a sense of social responsibility. Transplant Proc 2003;35(3):1153-1155.[http://dx.doi. org/10.1016/S0041-1345(03)00129-5]

2. Ghods AJ, Savaj S. Iranian model of paid and regulated living-unrelated kidney donation. Clin J Am Soc Nephrol 2006;1(6):1136-1145. [http://dx.doi.org/10.2215/ CJN.00700206]

3. Blackbeard M. Consent to Organ Transplantation. THRHR 2008;66(1):47-48.

4. Schicktanz S, Wiesermann C, Wohlke S. Teaching ethics in organ transplantation and tissue donation. Gottingen: Universitatverlag, 2010:4

5. Statz SE. Finding the winning combination: How blending organ procurement systems used internationally can reduce the organ shortage. Vanderbilt JTransnat
L 2006;(39):1690-1697.

6. World Health Organization. Human Organ Transplantation. Geneva: World Health Organization, 2014. http://www.who.int/transplantation/organ/en/ (accessed 24 November 2014).

7. Participants in the International Summit on Transplant Tourism and Organ Trafficking. The Declaration of Istanbul on Organ Trafficking and Transplant Tourism. Transplantation 2008;86(8):1013-1018. [http://dx.doi.org/10-1097/ TP.0b013e318185ffc9]

8. Lavee J, Ashkenazi T, Stoler A, Cohen J, Beyar R. Preliminary marked increase in the national organ donation rate in Israel following implementation of a new organ transplantation law. Am J Transplant 2013;(13):784-789. [http://dx.doi. org/10.1111/ajt.12001]

9. Venter B, Slabbert M. Rewarding a living kidney donor: A comparison between South Africa, Singapore and Iran. Obiter 2013;34(2):185-199.

10. Fry- Revere S. The Kidney Sellers: A journey of Discovery in Iran. Durham: Carolina Academic Press. 2014:8.

11. Major RWL. Paying kidney donors: Time to follow Iran? Mcgill J Med 2008:11(1):67-69.

12. Siegal G. Making the case for directed organ donation to registered donors in Israel. Isr J Health Policy Res 2014;3(1):1. [http://dx.doi.org/10.1186/2045-40153-1]

13. Cronin AJ. Points mean prizes: Priority points, preferential status and directed organ donation in Israel. Isr J Health Policy Res 2014;3(1):8..[http://dx.doi. org/10.1186/2045-4015-3-8]

14. Quigley M, Wright L, Ravitsky V. Organ donation and priority points in Israel: An ethical analysis. Transplantation 2012;93(10):970-973. [http://dx.doi.org/10.1097/ TP.0b013e31824e3d95]

15. August JG. Modern models of organ donation: Challenging increases of federa power to save lives. Hastings Constitutional Law Quarterly. 2013:40(2):394-422.

16. Lavee J, Ashkenazi T, Gurman G, Steinberg D. A new law for allocation of donor organs in Israel. Lancet 2009;375(9720):1131-1133. [http://dx.doi.org/10.1016/ SO140-6736(09)61795-5

17. Jotkowitz A. Notes on the new Israeli organ donation law - 2008. Transplant Proc 2008;40(10):3297-3298. [http://dx.doi.org/10.1016/j.transproceed.2008.08.128]

18. Satel S, Kidney M. Israel's remarkable new steps to solve its organ shortage. New York: The Slate Group Medical Examinier, 2010. http://www.slate.com/ articles/health_and_science/medical_examiner/2010/01/kidney_ (accessed 21 November 2014).

19. Wright L, Silva DS. Incentives for organ donation: Israel's novel approach. Lancet 2010;375(9722):1233-1234. [http://dx.doi.org/10.1016/S0140-6736(09)61520-8]

20. Slabbert $M$, Oosthuizen $H$. The payment for an organ and the admission of guilt by a South African hospital - The State v. Netcare Kwa-Zulu Natal (Pty) Ltd. Obiter 2011:32(3):740-746

21. Ravitsky V. Incentives for post-mortem organ donation: Ethical and cultural considerations. J Med Ethics 2013;39(6):381-382. [http://dx.doi.org/10.1136/ medethics-2013-101322]

22. National Kidney Foundation. Kidney Disease. Houghton: National Kidney Foundation, 2015. http://www.nkf.org.za/kidney_disease.htm\#startling_facts (accessed 22 April 2015)

23. National Kidney Foundation. Kidney Disease: How is it treated. Houghton National Kidney Foundation, 2015. http://www.nkf.org.za/kidney_disease. htm\#HOW_IS_IT_TREATED (accessed 22 April 2015).

24. Organ Donor Foundation. Transplant Statistics. Cape Town: Organ Donor Foundation, 2015. https://www.odf.org.za/2013-06-11-09-17-45/statistics.html (accessed 22 April 2015)

25. Republic of South Africa. Organ Transplant Act. Pretoria: Government Gazette, 2008.

26. Republic of South Africa. Organ Transplant Act, Section 23. Pretoria: Government Gazette, 2008.

27. Anonymous. Unhealthy SA lifestyles boost organ demand. Cape Town: Health 24.com, 2015. http://www.health24.com/News/Unhealthy-SA-lifestyles-boostorgan-demand-20140929 (accessed 22 April 2015).

28. Linde D. Israel, a leader in transplant tourism, finds a formula for increasing domestic donations. New York: Tablet Magazine, 2015. http://tabletmag.com/ jewish-news-and-politics/164976/israel-organ-donation/?print=1 (accessed 20 November 2014). 